\title{
Reproductive tract infections associated with vaginal discharge and their socio-demographic and reproductive determinants among clinic attendees in Bangladesh
}

\author{
Saifur Rahman ${ }^{1}$, Marian J. Currie ${ }^{2}$, Robert F. Breiman ${ }^{3}$, Masud Reza ${ }^{4}$, Motiur Rahman ${ }^{5}$, Khairun Nessa $^{6}$
}

${ }^{1}$ Epidemiologist \& Post Doctoral Research Fellow, Faculty of the Professions, University of New England, Armidale, NSW, Australia. ${ }^{2}$ Research Program Manager, Academic Unit of Internal Medicine, Canberra Hospital, Canberra, ACT, Australia. ${ }^{3}$ Division Director, ${ }^{6}$ Senior Operations Researcher, Health System and Infectious Diseases Division; ${ }^{4}$ Senior Manager, Surveillance, Monitoring and Evaluation; ICDDR,B: Knowledge for Global Lifesaving Solution, Dhaka, Bangladesh; ${ }^{5} \mathrm{Head}$ of Laboratories, Centre for Tropical Medicine, Oxford University Clinical Research Unit, HO CHi Minh City, Vietnam.

\begin{abstract}
Abnormal vaginal discharge is frequently associated with common sexually and non-sexually transmitted reproductive tract infections (RTIs) and the resultant poor reproductive health outcomes. However, there is scarce information concerning the prevalence and etiologies of these infections in women in Bangladesh. The aim of study was to determine the rates of, and socio-demographic and reproductive characteristics associated with, common RTIs in urban public health clinics in Dhaka, Bangladesh. An urban clinic-based sample of 1309 currently married women of reproductive age presenting with abnormal vaginal discharge was recruited. Consenting women were interviewed and tested for Candida, bacterial vaginosis, Trichomonas vaginalis, Neisseria gonorrhoeae and Chlamydia trachomatis during a speculum examination. Approximately 53\% (673/1309) of the participants had laboratory evidence of RTIs. The prevalence of Candida, bacterial vaginosis, T. vaginalis, $N$. gonorrhoeae and C. trachomatis were $32.4 \%, 22.4 \%, 3.1 \%, 2.1 \%, 1.9 \%$ respectively. Age, education, living in a slum, working outside the home, polygamous marriage and suspecting infidelity were independently associated with vaginal and cervical infections. Candidiasis and bacterial vaginosis were the most common infections in this population. Paying attention to the socio-demographic and reproductive characteristics found to be associated with RTIs can assist clinicians in identifying women at risk of these infections.
\end{abstract}

Keywords: Vaginal discharge, Reproductive tract infections, Socio-demographic and reproductive factors, Urban health clinics, Bangladesh.

\section{Introduction}

Reproductive Tract Infections (RTIs) including sexually transmissible infections (STIs) are of public health importance because of their negative effects on reproductive health including pelvic inflammatory disease (PID) and adverse pregnancy outcomes. ${ }^{1}$ In 2008 the World Health Organization estimated that 498.9 million people aged 15 to 49 years were infected worldwide with curable STIs such as gonorrhoea, chlamydia, syphilis and trichomoniasis. Of these infections, 78.5 million occurred in South and Southeast Asia, and more than half of those infected were female. ${ }^{2}$

Abnormal vaginal discharge is common among women in South Asia. ${ }^{3}$ It is a frequent symptom of common RTIs, which include endogenous infection with organisms such as Candida species (Candida) and Gardnerella vaginalis (G. vaginalis), as well as sexually transmitted pathogens such as Neisseria gonorrhoeae (N. gonorrhoeae), Chlamydia trachomatis (C. trachomatis) and Trichomonas vaginalis (T. vaginalis). ${ }^{4}$ G. vaginalis, Prevotella species, Mobiluncus species, and Mycoplasma hominis are commonly found in bacterial vaginosis, the polymicrobial clinical syndrome resulting from replacement of the

\section{Practice Points}

- Candidiasis and bacterial vaginosis are the most common infections among the urban primary health care clinic attendees complaining of abnormal vaginal discharge.

- Caution should be exercised in diagnosing RTIs from the presence of vaginal discharge alone.

- Socio-demographic and reproductive characteristics offer some guidance to clinicians in identifying women at risk of bacterial vaginosis and candidiasis.

- Women with vaginal discharge and a history of poor obstetric outcomes may benefit from testing for and treatment of common RTIs.

- Education of clinicians and women to enable discrimination between physiological and pathological vaginal discharge may reduce patient anxiety and the burden on health services.

Correspondence: Md. Saifur Rahman, Faculty of the Professions, University of New England, Armidale, NSW 2351, Australia. Email: srahman8@une.edu.au.

South East Asia Journal of Public Health 2012;2(2):67-72. (C) 2012 Rahman et al., publisher and licensee Public Health Foundation Bangladesh. This is an Open Access article which permits unrestricted non-commercial use, provided the original work is properly cited. 
normal H2O2-producing Lactobacillus species in the vagina with high concentrations of anaerobic bacteria. ${ }^{5}$

More than a decade ago, the Hospital Directorate of Family Planning and Population Control in Bangladesh found that $83 \%$ of married women of reproductive age suffered from abnormal vaginal discharge. ${ }^{6}$ The Bangladesh Bureau of Statistics identified abnormal vaginal discharge as one of the three leading reproductive morbidities during a survey conducted in 1997 among urban and rural females of reproductive age. The other morbidities were anaemia and menstrual disorders. ${ }^{7}$ A community based study in rural Bangladesh reported vaginal discharge as the most common illness. ${ }^{8}$

Very little published data concerning the sociodemographic and reproductive characteristics of women with vaginal discharge can be found in Bangladesh. Such knowledge can assist health care providers to make decisions on empiric therapy and identify at-risk populations, as well as offering guidance to policy makers concerning the management of RTIs. The aim of study was to determine the rates of, and socio-demographic and reproductive characteristics associated with, common RTIs in urban public health clinics in Dhaka, Bangladesh.

\section{Materials and methods}

In a cross-sectional study conducted in urban public health clinics in Dhaka, Bangladesh, married women who presented at five public health clinics located in five urban areas of Dhaka City: Tejgoan, Manikdi, Shajadpur, Lalbagh and Gandaria with vaginal discharge between from June 2001 and July 2002 were consecutively recruited. The five clinics comprised a convenience sample chosen because of their close proximity to the reference laboratory (at RTI/STI Research Laboratory of ICDDR, B) to ensure that collected specimens were maintained at optimal temperatures calculated to optimise the accuracy of laboratory tests.

To be eligible for inclusion in the study women needed to report vaginal discharge as the primary reason for clinic attendance and consent in writing to an interview and the collection of vaginal and cervical specimens for laboratory investigation of RTIs. They also needed to be currently-married, of reproductive age (15-49 years), be willing to undergo a speculum examination and not be menstruating at the time of the interview and specimen collection. Cases of RTIs were defined as laboratory evidence of candidiasis, bacterial vaginosis, trichomoniasis, gonorrhoea or chlamydia.

The study was supported by USAID-Dhaka and was conducted by staff from the International Centre for Diarrhoeal Disease Research, Bangladesh (ICDDR, B) under the Knowledge for Global Lifesaving Solution program in collaboration with Pragoti Samaj Kallyan Prathisthan, Concerned Women for Family Development and Engender Health. The study was approved by the Ethical Review Committee of ICDDR, B.

\section{Laboratory aspects}

Vaginal and cervical specimens were collected from the posterior fornix of the vagina and the endocervix respectively. Immediately after the collection, each specimen was refrigerated at one of the five clinics at $4-8^{\circ} \mathrm{C}$ immediately after the collection. At the end of each day, all specimens were transported to the RTI/STI Research Laboratory observing the cold chain for laboratory procedures to detect RTIs.

Vaginal swabs were tested for Candida using microscopy and culture on Sabouraud's dextrose agar, bacterial vaginosis using Gram-stained smear for microscopy using Nugent's criteria and T. vaginalis using InPouch TV (Biomed Diagnostics San Jose, CA, USA) and the endocervical specimens for $C$. trachomatis and $N$. gonorrhoea using AMPLICOR (Roche diagnostic Systems Inc., Branchuburg, NJ, USA). A culture plate with a growth of more than 50 Candida colony count was considered as positive for Candida. Diagnosis of bacterial vaginosis was based on Nugent's scoring of Gram stain high vaginal swabs.

\section{Data analysis}

Results were analysed using STATA Version 10 (Stata Corporation, College Station, TX, USA). Infection rates are reported as simple percentages. Associations between the outcome variables (RTIs) and the explanatory variables (socio-demographic and reproductive characteristics) were measured using Pearson chi-square tests. Variables demonstrating a Wald $p$-value of less than 0.25 in bivariate analysis were included in the multivariable models. Multivariable logistic regression models were estimated for each of the four outcome variables (bacterial vaginosis, Candida, T. vaginalis and cervical infection caused by $N$. gonorrhoeae or C. trachomatis). Chlamydia and gonorrhea infections are often considered together because of the frequency of co-infection, similarities in transmission and clinical presentation. ${ }^{9}$

\section{Results}

A total of 1309 women were investigated for common vaginal and cervical infections. The median age of participants was 25 years (range 15-48 years) with $71.4 \%$ aged below 30 years and $1.3 \%$ aged 45 or older. $26.5 \%$ of women had never attended school. Polygamous marriages were reported by $14 \%$ of women with the number of additional marriages ranging from one to seven. $356 / 1309(27.2 \%)$ women lived in densely populated urban areas with a low standard of living (slums) and the rest lived in their own or rented houses or in government quarters. $25.7 \%$ of the women were working, with the majority $(73.5 \%)$ engaged in the garment manufacturing industry.

The majority of participants $(76.6 \%)$ reported that their husbands had completed at least one year of schooling, with $36.4 \%$ working in small business, $35.1 \%$ in offices, and $28.5 \%$ as daily wage-earners. $12.1 \%$ of women reported that their husbands worked outside Dhaka city. 
Eight percent of women were nulliparous and 9.2\% were pregnant. Of the $59.5 \%(779 / 1309)$ using contraception, 5\% (38/779) used traditional methods (periodic abstinence, withdrawal, and lactational amenorrhoea) and 95\% (741/779) used "modern methods" that included hormonal contraception (35.6\%), condoms $(12.5 \%)$ and intrauterine contraceptive devices (8.6\%). Approximately 41\% (533/1309) of women reported having had at least one abortion with $30.2 \%$ (161/533) of these reporting an induced abortion.

\section{Prevalence of RTIs}

Overall, 53.2\% (696/1309) of the participants had laboratory evidence of RTIs, 51.4\% (673/1309) had vaginal infections and 3.8\% (50/1309) had cervical infections. Table 1 shows the prevalence of bacterial vaginosis, candidiasis, trichomoniasis, gonorrhoea and chlamydia infections among the study population. Of those with vaginal infections, endogenous infections were detected in $97.5 \%(656 / 673)$, with $64.6 \%(424 / 656)$ caused by Candida and $35.4 \%(232 / 656)$ caused by bacterial vaginosis. Infections with both Candida and bacterial vaginosis were detected in $9.3 \%(61 / 656)$ of women and 103 women were positive for more than one infection (Table 2). Most of these women were positive for two infections, with two women positive for three infections. Bacterial vaginosis was positively associated with $T$. vaginalis, $C$. trachomatis and $N$. gonorrhoeae infections and negatively associated with Candida infections (Table 3).

Table 1: Prevalence of common reproductive tract infections (n-1309)

\begin{tabular}{|l|c|c|c|}
\hline \multirow{2}{*}{ Common RTIs } & \multirow{2}{*}{$\begin{array}{c}\text { Number } \\
\text { of cases* }\end{array}$} & \multicolumn{2}{|c|}{ Prevalence } \\
\cline { 3 - 4 } & $\mathbf{( \% )}$ & $\mathbf{9 5 \%}$ CI \\
\hline Candida & 424 & 32.4 & $29.8-34.9$ \\
\hline Bacterial vaginosis & 293 & 22.4 & $20.1-24.6$ \\
\hline T. vaginalis & 40 & 3.1 & $2.1-3.9$ \\
\hline N. gonorrhoea & 28 & 2.1 & $1.4-2.9$ \\
\hline C. trachomatis & 26 & 1.9 & $1.2-2.7$ \\
\hline
\end{tabular}

*Includes women with more than one infection

Table 2: Pattern of co-existence of infections

\begin{tabular}{|l|c|}
\hline Pattern of co-existence of infections & $\begin{array}{c}\text { Number of } \\
\text { cases* }\end{array}$ \\
\hline Candida + bacterial vaginosis & $61(59.2 \%)$ \\
\hline Bacterial vaginosis + cervical infection & $19(18.4 \%)$ \\
\hline T. vaginalis + bacterial vaginosis & $18(17.5 \%)$ \\
\hline Candida + cervical infection & $12(11.6 \%)$ \\
\hline Candida $+T$. vaginalis & $7(6.8 \%)$ \\
\hline $\begin{array}{l}\text { Bacterial vaginosis, Candida }+T . \\
\text { vaginalis }\end{array}$ & $2(1.9 \%)$ \\
\hline Trichomoniasis + cervical infection & $2(1.9 \%)$ \\
\hline
\end{tabular}

*Among 103 women who had at least more than one infection

\section{Socio-demographic characteristics}

The socio-demographic and reproductive factors associated with the commonly occurring RTIs varied between infections with adjusted odds ratios ranging from 0.7 to 4.6 (Table 4). Younger women were more likely to have chlamydia or gonorrhoea, while older women were more likely to have bacterial vaginosis. Women who lived in slums were more likely to test positive for bacterial vaginosis and trichomoniasis, while those reporting an absence of school-based education were less likely to have candidiasis but more likely to have trichomoniasis. Women's whose husbands were polygamous were more likely to have trichomoniasis and those who suspected their husbands of being unfaithful were more likely to have chlamydia or gonorrhea. Pregnant women were more likely to have candidiasis while nulliparous women were more likely to have bacterial vaginosis and/or trichomoniasis. Using an intrauterine contraceptive device was associated with bacterial vaginosis.

\section{Discussion}

We found that more than half of women who were concerned about their vaginal discharge tested positive for one or more RTIs. Consistent with other studies conducted in Bangladesh ${ }^{10,11}$ we found high rates of bacterial vaginosis $(22.4 \%)$ and candidiasis $(32.4 \%)$ and low rates of trichomoniasis $(3.1 \%)$, chlamydia $(1.9 \%)$ and gonorrhea $(2.1 \%)$. Hawkes et al. ${ }^{10}$ and Bogaerts et al. ${ }^{11}$ reported prevalence rates of bacterial vaginosis, candidiasis, trichomoniasis, chlamydia and gonorrhea as $18.9 \%$ and $29 \%, 4.7 \%$ and $12.6 \%, 3.7 \%$ and $1.5 \%, 0.5 \%$ and $0.9 \%$, and $0.5 \%$ and $0.2 \%$ respectively. The wide variation in the reported prevalence rates may result from methodological disparities such as the use of a variety of laboratory methods and different population groups such as family planning clinic attendees, hospital outpatients, rural community patients, sex workers and urban non-government organization attendees.

The $3.8 \%$ prevalence of cervical infections caused by either $N$. gonorrhoea or $C$. trachomatis found in this study is comparable to the $2.2 \%$ rate obtained in a clinic -based sample of married clinic attendees in urban Bangladesh $^{12}$ and the 3.2 to $5 \%$ found among community and clinic based studies in India. ${ }^{13,14}$ These prevalence rates are much lower than those reported in Africa and Central America, ${ }^{2}$ although, as in many other studies, we found chlamydia infection rates to be higher in younger women $(4.3 \%$ in women aged $<30$ years vs. $1.7 \%$ in women 30 years or more).

Bangladesh is one of the most conservative countries in the world and it is believed that most married women of Bangladesh do not have sexual relationships outside the marriage. ${ }^{15}$ However, Caldwell et al. found that $7 \%$ of married men in Bangladesh had sexual relationships with sex workers and less than $10 \%$ of those used condoms. ${ }^{15}$ A study conducted in 2005 reported that $15.5 \%$ of brothel-based sex workers had gonorrhea and 7.5\% tested positive for chlamydia. ${ }^{16}$ It can be assumed that women infected with chlamydia or gonorrhea were infected by their husbands.

South East Asia Journal of Public Health 2012;2(2):67-72. 
Table 3: Associations between bacterial vaginosis (BV) and other common RTIs (n-1309)

\begin{tabular}{|c|c|c|c|c|c|c|}
\hline \multirow[t]{3}{*}{ Infection } & \multicolumn{4}{|c|}{ Presence of co-existing infection } & \multirow{3}{*}{$\begin{array}{c}\text { Unadjusted } \\
\text { OR } \\
(95 \% \text { CL) }\end{array}$} & \multirow{3}{*}{$\begin{array}{c}\text { *Adjusted } \\
\text { OR } \\
(95 \% \text { CL) }\end{array}$} \\
\hline & \multicolumn{2}{|c|}{ Yes } & \multicolumn{2}{|c|}{ No } & & \\
\hline & Cases (\%) & $\%+$ +ve BV & Cases (\%) & $\%+$ ve BV & & \\
\hline Candida & $424(32.4 \%)$ & 14.4 & $885(67.6)$ & 26.2 & $0.5(0.3-0.6)$ & $0.5(0.4-0.7)$ \\
\hline T. vaginalis & $40(3.1 \%)$ & 6.1 & $1269(96.9)$ & 2.2 & $3.0(1.6-5.6)$ & $2.7(1.4-5.2)$ \\
\hline NG and/or CT & $50(3.8 \%)$ & 38.0 & $1259(96.2)$ & 21.8 & $2.2(1.2-4.0)$ & $2.1(1.2-3.8)$ \\
\hline
\end{tabular}

*Adjusted for other co-existing infections

Table 4: Socio-demographic characteristics of women attending the clinics (n-1309)

\begin{tabular}{|c|c|c|c|c|}
\hline \multirow{2}{*}{ Characteristics } & \multicolumn{2}{|c|}{$\%$ with characteristic } & \multirow{2}{*}{ Adjusted } & \multirow{2}{*}{$p$-value } \\
\hline & Infected & Uninfected & & \\
\hline \multicolumn{5}{|l|}{ Candida (n-424) } \\
\hline Had no education & 22.9 & 28.2 & $0.7(0.5,0.9)$ & $<0.05$ \\
\hline Currently pregnant & 16.5 & 5.7 & $3.4(2.2,4.8)$ & $<0.001$ \\
\hline \multicolumn{5}{|l|}{ Bacterial vaginosis (n-293) } \\
\hline Never been pregnant & 14.7 & 7.1 & $2.3(1.5,3.7)$ & $<0.001$ \\
\hline Working outside house & 37.9 & 22.2 & $2.1(1.6,2.8)$ & \\
\hline Age $35+$ & 20.1 & 11.2 & $2.0(1.3,2.7)$ & $<0.001$ \\
\hline Using IUD & 12.6 & 7.4 & $2.0(1.3,3.3)$ & $<0.001$ \\
\hline Living in slum & 34.1 & 24.2 & $1.6(1.2,2.1)$ & $<0.01$ \\
\hline \multicolumn{5}{|l|}{ Trichomonas vaginalis (n-40) } \\
\hline Never been pregnant & 22.5 & 8.3 & $4.6(2.0,10.5)$ & $<0.001$ \\
\hline Husband with multiple marriages & 37.5 & 12.9 & $3.1(1.5,6.3)$ & $<0.01$ \\
\hline Living in slum & 55.0 & 26.3 & $2.8(1.4,5.6)$ & $<0.01$ \\
\hline Had no education & 55.0 & 25.6 & $2.2(1.1,4.4)$ & $<0.05$ \\
\hline \multicolumn{5}{|c|}{ N. gonorrhoeae or C. trachomatis (n-50) } \\
\hline Women aged $<31$ years & 92 & 81 & $2.7(1.0-7.6)$ & 0.05 \\
\hline Suspecting husband's infidelity & 30 & 18 & $1.9(1.1-3.6)$ & $<0.05$ \\
\hline
\end{tabular}

*The adjusted odds ratios and 95\% confidence intervals were derived from a logistic model that included age, education, working status, living in slum, number of children, husband's education, husband's occupation, husband's

The high rates of bacterial vaginosis and candidiasis found in this population are of concern. There is evidence that these two infections are associated with adverse pregnancy outcomes, including premature rupture of the membranes, preterm labor, preterm birth, intra-amniotic infection and postpartum endometritis. ${ }^{17}$ Kiss et al. reported a $46 \%$ reduction in the preterm birth rate in a randomized controlled trial of screening (15 and 19 weeks gestation) and treatment of asymptomatic bacterial vaginosis, candidiasis and/ or trichomoniasis in early pregnancy. ${ }^{18}$ Post-hoc subgroup analyses of this trial suggest the benefit was primarily among those women who were treated for asymptomatic candidiasis.

Bacterial vaginosis is also associated with PID and subsequent tubal factor infertility. ${ }^{5}$ The bacterial flora that characterise bacterial vaginosis have been recovered from the endometria and salpinges of women with pelvic inflammatory disease (PID). ${ }^{19}$ We found the presence of bacterial vaginosis was associated with testing positive for other infections. In our study women testing positive for bacterial vaginosis were twice as likely to have trichomoniasis, chlamydia and/ or gonorrhea. In 2003, Begum et al. ${ }^{20}$ found that $54 \%$ of women diagnosed with PID tested positive for bacterial vaginosis. This finding is supported by a more recent study where women with high Nugent scores (9 and 10) had a 2.1 fold increased risk (95\% CI 1.1-4.3) of testing positive for chlamydia, gonorrhea, trichomoniasis or PID. $^{21}$

It is important to note that almost half of the women in this study who complained of abnormal vaginal discharge did not have laboratory confirmed infection. It may be that these women are infected with organisms not detected by currently employed laboratory methods. Testing by nucleic acid amplification techniques (NAAT) may have identified pathogens, such as $M y-$ coplasma genitalium (M. genitalium), ${ }^{22}$ which could explain the presence of vaginal discharge. We later tested the samples collected during this study using NAAT and found that $0.8 \%$ of women were infected with M. genitalium. ${ }^{22}$

We had hoped to offer clinicians and policy makers some evidence to direct care both at the bedside and at a population level. However, it is difficult to interpret the 
relatively weak associations between the sociodemographic characteristics of the women in the sample and each of the infections. We found that women with no education were less likely to have candidiasis than those with some education. Namkinga et l. $^{23}$ and Bradshaw et $a l .{ }^{24}$ reported a similar association. It is possible that educated women are more aware of genital hygiene and are more likely to use soap and water or other chemical agents to keep their genitals clean thus disturbing their vaginal flora.

We found that women aged more than 35 years, women working outside their home and women who lived in slums were more likely to have bacterial vaginosis. Calzolari et $a l^{25}$ found an association between bacterial vaginosis and older age. However, the association between woman working out of the home and bacterial vaginosis has never been reported by any other studies. It is possible that working women experience more psychosocial stress, which other authors have suggested increases the risk of bacterial vaginosis by lowering their immune function. ${ }^{26}$

Using an IUD and being nulliparous were found to be associated with bacterial vaginosis in our study. A biological explanation for this could that the presence of a neutrophil elastase inhibitor known as secretory leukocyte protease inhibitor (SLPI) in human cervical mucosa. SLPI is regulated by progesterone and therefore is found in higher concentrations in pregnant women. SLPI has antibacterial, antiviral and antifungal actions and has a role in the demand of suppressed inflammatory responses in the uterus during pregnancy. ${ }^{27}$

We found that women who had no school-based education, women who lived in slums and women whose husbands were in polygamous marriages were more likely to have trichomoniasis and that these findings were supported by other studies. ${ }^{12,28}$ Our finding that cervical STIs were associated with suspected infidelity is also supported by previous studies. ${ }^{12}$

The findings of this study may not be generalized to all married women complaining of vaginal discharge. The five study clinics were chosen because of their proximity to the ICDDR, B RTI/STI research laboratory in an effort to maintain the integrity of the clinical specimens. It is possible that the clinics, and the women who attended them, differed in some way from other clinics and other married women in Dhaka City with a similar complaint. The large sample and the use of best practice laboratory methods are strengths of this study.

\section{Conclusion}

The study found that the rate of non-sexually transmitted RTIs was significantly higher than the rate of STIs among married women with abnormal vaginal discharge attending urban public health clinics in Dhaka who were concerned about vaginal discharge. These findings have significant repercussions for the reproductive health of this population and should be the primary focus of clinical care and policy formulation in this resource poor setting in Bangladesh. Caution should be exercised in diagnosing RTIs from the presence of vaginal discharge alone, as almost half of the women complaining of this symptom did not have a common RTI. Sociodemographic and reproductive characteristics can offer some support to clinical and policy decisions.

\section{Acknowledgement}

We would like to thank United States Agency for International Development (USAID); Laboratory Science Division, ICDDR, B, Dhaka, Bangladesh; Progiti Samaj Kallyan Prothisthan (PSKP), Dhaka, Bangladesh; Concerned Women for Family Development (CWFD), Dhaka, Bangladesh for their support to conduct this research.

\section{Funding}

United States Agency for International Development (USAID), Dhaka, Bangladesh.

\section{References}

1. Germain A, Holmes KK, Plot P, Wasserheit JN, eds. Reproductive tract infections: global impact and priorities for women's health. New York: Plenum Press, 1992.

2. WHO. Global incidence and prevalence of selected curable sexually transmitted infections 2008. Geneva: World Health Organization, 2012.

3. Madhivanan $\mathrm{P}$, Krupp K, Chandrasekaran V, Karat C, Arun A, Cohen CR, et al. Prevalence and correlates of bacterial vaginosis among young women of reproductive age in Mysore, India. Indian J. Med Microbiol 2008;26:132-7.

4. Patel DA, Burnett NM, Curtis KM. Reproductive tract infections. Atlanta: Department of Health and Human Services, Centre for Disease Control and Prevention, National Centre for Chronic Disease Prevention and Health Promotion, Division of Reproductive Health, Georgia, USA, 2003.

5. Center for Disease Control and Prevention. Management of patients who have vaginal discharge. http://www.cdc.gov/std/treatment/2006/vaginaldischarge.htm\#vagdis2 (accessed Nov 2012)

6. Ministry of Health and Family Welfare. Strengthening RTI/STD services: lessons learned from health and family welfare centres. Dhaka: Population Council, 1998.

7. Islam W, Hossain MS. Reproductive health status in Bangladesh 1997. In: Ministry of Planning SD, Health and Demographic Survey, editors. Monographi series-06. Dhaka: Bangladesh Bureau of Statistics, 1997.

8. Sing M, Khan RJ. A cultural explanatory model for white discharge amongst women in Kakaboo 
village, Bangladesh. BUJ 2006; 3:17-26.

9. World Health Organization. Sexually transmitted and other reproductive tract infections: A guide to essential practice. http://www.popcouncil.org/ pdfs/frontiers/reports/RTIS GEP FINALl.pdf (Accessed Nov 2012)

10. Hawkes S, Morison L, Foster S, Gausia K, Chakraborty J, Peeling RW, et al. Reproductive tract infections in women in low-income, lowprevalence situations: assessment of syndromic management in Matlab, Bangladesh. Lancet $1999 ; 354: 1776-81$.

11. Bogaerts J, Ahmed J, Akhter N, Begum N, Van Ranst M, Verhaegen J. Sexually transmitted infections in a basic healthcare clinic in Dhaka, Bangladesh: syndromic management for cervicitis is not justified. Sex Transm Infect 1999; $75: 437-8$

12. Bogaerts J, Ahmed J, Akhter N, Begum N, Rahman $M$, Nahar $S$ et al. Sexually transmitted infections among married women in Dhaka, Bangladesh: unexpected high prevalence of herpes simplex type 2 infection. Sex Transm Infect 2001;77:114-9.

13. George R, Thomas K, Thyagarajan SP, Jeyaseelan L, Peedicayil A, Jeyaseelan V, et al. Genital syndromes and syndromic management of vaginal discharge in a community setting. Int $J S T D$ AIDS 2004;15(6):367-70.

14. Vishwanath S, Talwar V, Prasad R, Coyaji K, Elias CJ, de Zoysa I. Syndromic management of vaginal discharge among women in a reproductive health clinic in India. Sex Transm Infect 2000;76:303-6.

15. Caldwell B, Pieris I, Barkate K, Caldwell J, Caldwell P. Sexual regimes and sexual networking: the risk of an HIV/AIDS epidemic in Bangladesh. Soc Sci Med 1999; 48:1103-16.

16. Nessa K, Waris SA, Alam A, Huq M, Nahar S, Chawdhury FA, et al. Sexually transmitted infections among brothel-based sex workers in Bangladesh: high prevalence of asymptomatic infection. Sex Transm Dis 2005; 32:13-9.

17. Donders GG, Van Calsteren K, Bellen G, Reybrouck R, Van den Bosch T, Riphagen I, et al. Predictive value for preterm birth of abnormal vaginal flora, bacterial vaginosis and aerobic vaginitis during the first trimester of pregnancy. Int J Gynecol Obstet 2009;116:1315-24.
18. Kiss H, Petricevic L, Husslein P. Prospective randomised controlled trial of an infection screening programme to reduce the rate of preterm delivery. BMJ 2004;329:371.

19. Deb K, Chaturvedi MM, Jaiswal YK. Comprehending the role of LPS in Gram-negative bacterial vaginosis: ogling into the causes of unfulfilled child-wish. Arch Gynecol obstet 2004;270:133-46.

20. Begum A, Nilufar S, Akther K, Rahman A, Khatoon F, Rahman M. Prevalence of selected reproductive tract infections among pregnant women attending an urban maternal and childcare unit in Dhaka, Bangladesh. J Health Popul Nutr 2003; 21:112-6.

21. Allsworth JE, Peipert JF. Severity of bacterial vaginosis and the risk of sexually transmitted infection. Am J Obstet Gynecol 2011;133-46

22. Rahman S, Garland S, Currie M, Tabrizi SN, Rahman M, Nessa K, et al. Prevalence of Mycoplasma genitalium in health clinic attendees complaining of vaginal discharge in Bangladesh. Int J STD AIDS 2008; 19:772-4.

23. Namkinga LA, Matee MI, Kivaisi AK, Moshiro C. Prevalence and risk factors for vaginal candidasis among women seeking primary care for genital infrections in Dar es Salaam. East Afr Med J 2005; 82:138-43.

24. Bradshaw CS, Morton AN, Garland SM, Morris MB, Moss LM, Fairley CK. Higher-risk behavioral practices associated with bacterial vaginosis compared with vaginal candidiasis. Obstet Gynecol 2005;106:105-14.

25. Calzolari E, Masciangelo R, Milite V, Verteramo $\mathrm{R}$ : Bacterial vaginosis and contraceptive methods. Int J Gynaecol Obstet 2000; 70:341-6.

26. Harville EW, Savitz DA, Dole N, Thorp JM, Jr., Herring AH. Psychological and biological markers of stress and bacterial vaginosis in pregnant women. BJOG 2007; 114:216-23.

27. King AE, Critchley HOD, Kelly RW. Presence of secretary leukocyte protease inhibitor in human endometrium and first trimester decidua suggests an antibacterial protective role. $\mathrm{Mol}$ Hum Reprod 2000;6:191-6.

28. Helms DJ, Mosure DJ, Peterman TA, Metcalf CA, Douglas J, Malotte CK, et al. Risk factors for prevalent and incident Trichomonas vaginalis among women participating in randomized, controlled tiral. Sex Transm Dis 2008;35:484-8. 